\title{
The Influence of Neurological Rehabilitation on Patients' Quality of Life After Ischemic Stroke: A Prospective Study in Romania
}

\author{
Thomas Gabriel Schreiner
}

\begin{abstract}
Background: Stroke is a public health problem in Romania, with important medical, social and financial implications, and sustained efforts are being made to improve post-stroke rehabilitation phase. A significant concern nowadays is the patient's quality of life (QOL); a successful stroke recovery therapy implies the increasing of QOL index. However, there are very few studies evaluating patients' QOL after stroke in Romania. In this context, the aim of this study was to evaluate the benefits that 1-year rehabilitation therapy brings to a patient with a history of ischemic stroke, highlighting the factors that influence the QOL index.
\end{abstract}

Methods: A prospective study was conducted in which the QOL (calculated using the stroke-specific QOL (SSQOL) questionnaire) was measured in a group of 40 patients who had suffered an ischemic stroke in the left middle cerebral artery territory and benefited from rehabilitation therapy for 1 year. Patients admitted in our Neurology Department between January 2018 and June 2019 were divided into several subgroups according to age, gender, domicile, educational level, familial support and comorbidities. Statistical data were processed in SPSS v.20.

Results: Among the individual factors studied, young age (under 60) showed a positive impact on QOL improvement after 1 year of stroke rehabilitation therapy $(\mathrm{P}=0.005)$. This was explained by the young patient's profile, with urban domicile ( $55 \%$ vs. $45 \%)$, higher educational level (60\% vs. $40 \%)$ and family support. The best recovered functions as noted by the questionnaire were language (18.25 \pm 4.95 ; $\mathrm{P}=0.015)$, upper motor functions $(21.50 \pm 2.70 ; \mathrm{P}=0.039)$, personality $(12 \pm 0.81 ; \mathrm{P}=0.032)$ and family roles $(11.53 \pm 1.81 ; \mathrm{P}=0.007)$. On the other hand, patient's gender (male $155.55 \pm 31.21$ vs. female $152.94 \pm 28.14)$ did not influence the outcome of the therapy $(\mathrm{P}=$ $0.267)$.

Conclusion: Stroke rehabilitation treatment is an essential compo-

Manuscript submitted May 8, 2020, accepted May 20, 2020

Published online May 30, 2020

Neurology Department, Clinical Hospital of Rehabilitation, Iasi, Romania. Email: schreiner.thomasgabriel@yahoo.com

doi: https://doi.org/10.14740/jnr596 nent for improving the QOL of the patient after stroke; it has become topic of concern in the literature nowadays. This work complements the existing data on this topic for stroke patients in Romania.

Keywords: Stroke; Rehabilitation; Quality of life; Romanian cohort

\section{Introduction}

Among neurological diseases in adults, stroke ranks first in terms of frequency and importance, therefore the topic of poststroke rehabilitation is significant and in continuous transformation [1-3].

Worldwide, stroke is one of the leading causes of morbidity and mortality [4]. Prospective studies show that it will become the main cause of mortality by $2030[5,6]$. From a recovery perspective, stroke is the leading cause of serious longterm disability in the USA [7] and in other developed countries [8], and also the second leading cause of dementia and the most common cause of epilepsy in the elderly [9], representing substantial economic burden.

In Romania, stroke is a real health problem because of high incidence, high related mortality and significant consequences on the motor and cognitive performances of the survivors [10]. Stroke sequelae can have catastrophic effects on the quality of life (QOL) of the patient and their family as well as negative socio-economic effects [11-13].

However, there are very few studies evaluating patients' QOL after stroke in Romania. Nowadays, besides the assessment of improvements related to motor deficit and aphasia, patients are observed from other perspectives such as emotional, cognitive and community involvement $[14,15]$. This holistic perspective defines the QOL.

Although there are many definitions of this concept, an adequate and measurable definition is elusive. Various "objective" and "subjective" indicators across a range of disciplines and scales, besides recent work on subjective well-being surveys and the psychology of happiness, have spurred renewed interest [16].

QOL means, for many, life satisfaction encompassing several dimensions: social, physical/motor, emotional and cognitive [17]. QOL is also an important parameter to monitor the recovery process in patients undergoing post-stroke 
rehabilitation [18]. Recent studies worldwide are concerned with the factors that could influence QOL and rehabilitation outcome [19]. Elements such as activity, ability to move, communication skills, degree of dependence, degree of social interaction and satisfaction of professional performance are just a few components found under the umbrella of the term QOL $[20,21]$. It should be noted, however, that these concepts also differ from individual to individual, depending on age, gender, living environment, education level and aspects that are under-studied in Romania and initially in other countries $[22,23]$.

In this context, the purposes of this study were to analyze the impact of neurological rehabilitation on the QOL of ischemic stroke patients in a clinical university hospital in Romania and to determine the relationship between QOL and individual characteristics.

\section{Materials and Methods}

\section{Subjects}

We conducted a prospective study on a group of 40 patients admitted in our Neurology Department from January 2018 to June 2019. Patients enrolled in the study had an ischemic stroke in the left middle cerebral artery (clinically and radiographically confirmed) for the first time, regardless of the mechanism of production. They were subsequently divided into several subgroups according to different criteria (age, social background, gender and risk factors). Other clinical relevant data for the etiology and secondary prevention of stroke were noted; however, not all data were included in this study.

In order not to alter the results, strict exclusion criteria were used: age below 18 years (our clinic is an adult clinic, all patients were above 18), an ischemic or hemorrhagic stroke in the medical history besides the last one, other neurological diseases associated with the onset of stroke (Parkinson's disease, Alzheimer's dementia and other neurodegenerative diseases), fluctuating stroke with no acute ongoing neurologic developments (relapse), dementia on minimal state examination (of < 22) (due to inability to directly communicate), history of ongoing psychoactive substance abuse, presence of psychiatric morbidity before and after stroke which specifically includes manic disorders, schizophrenia and associated terminal diseases such as renal failure or end-stage cancer.

Patients come from several counties in the North-East region of Romania, from both rural and urban areas, and the cohort was significant for the general population of the region. Patients arrived at our department after being treated in the acute phase (at least the first 10 - 14 days after stroke) in an acute care clinic to initiate recovery treatment.

Patients were consulted clinically and evaluated using two tests/questionnaires (stroke-specific quality of life (SSQOL) questionnaire and mini-mental state examination (MMSE) test) at the first clinic admission and then 12 months after the start of recovery therapy. We selected the 1-year period as a reference after consulting the literature which states that the most significant progress is recorded in the first 12 months af- ter the start of recovery.

\section{SSQOL questionnaire and its Romanian version}

SSQOL questionnaire was used as it is one of the most specific questionnaires for determining QOL in stroke patients [24]. It consists of 49 questions/items, structured into 12 main subscales/subdomains: self-control (five questions), view (three questions), mobility (six questions), work/productivity (three questions), upper limb functionality (five questions), language (five questions), thinking (three questions), personality (three questions), disposition (five questions), social role (five questions), family role (three questions) and energy (three questions). The patients' answers were evaluated on a scale of 1 to 5 .

The items of the SSQOL questionnaire present an adequate distribution with simple items for people with a higher degree of restriction from a participatory perspective and difficult items for those with few participation restrictions. All items have demonstrated adequate reliability [25]. Many studies showed that SSQOL is a useful clinical tool for assessing the QOL of stroke survivors [26].

This questionnaire, although exhaustive and with a long duration of application (approximately $15 \mathrm{~min} /$ patient), was selected because it addresses several essential areas of the patient's life. The translated Romanian version of the questionnaire was administered at the initiation of therapy and after 1 year. During this period, the patients benefited from physiokinetotherapeutic and aphasiologic treatment, both in our clinic (repeated hospitalizations of 12 - 14 days every 3 months), with daily continuation of the learned exercises in other clinics/medical centers specialized in rehabilitation [27].

In order to use the Romanian language version of this questionnaire, a committee of national experts in neurology, stroke and rehabilitation along with translators specialized in medical language was formed. Via forward and backward translation, they approached this task from two perspectives: the linguistic validation (when the equivalence of concepts in the questionnaire was assessed) and the cultural validation (when the concepts were tested with respect to the target culture - Romanian culture). Although validated in other languages [28, 29], the questionnaire was already used in Romania in other studies but no official validation had been recognized yet.

\section{Statistical analysis}

Regarding data processing, continuous variables were presented as mean \pm standard deviation and were compared using the Student's $t$-test. Categorical variables were expressed as numbers and/or percentages and were compared as a Pearson's Chi-squared test. All statistical tests, conducted in IBM SPSS Statistics version 20, were two-tailed with a $\mathrm{P}$ value $<0.05$ which was considered statistically significant.

This study was approved by the institutional ethical committee and the chief doctor of the neurology clinic at that time. The study was conducted in accordance with the principles of 
Table 1. Social, Clinical and Individual Characteristics of Patients

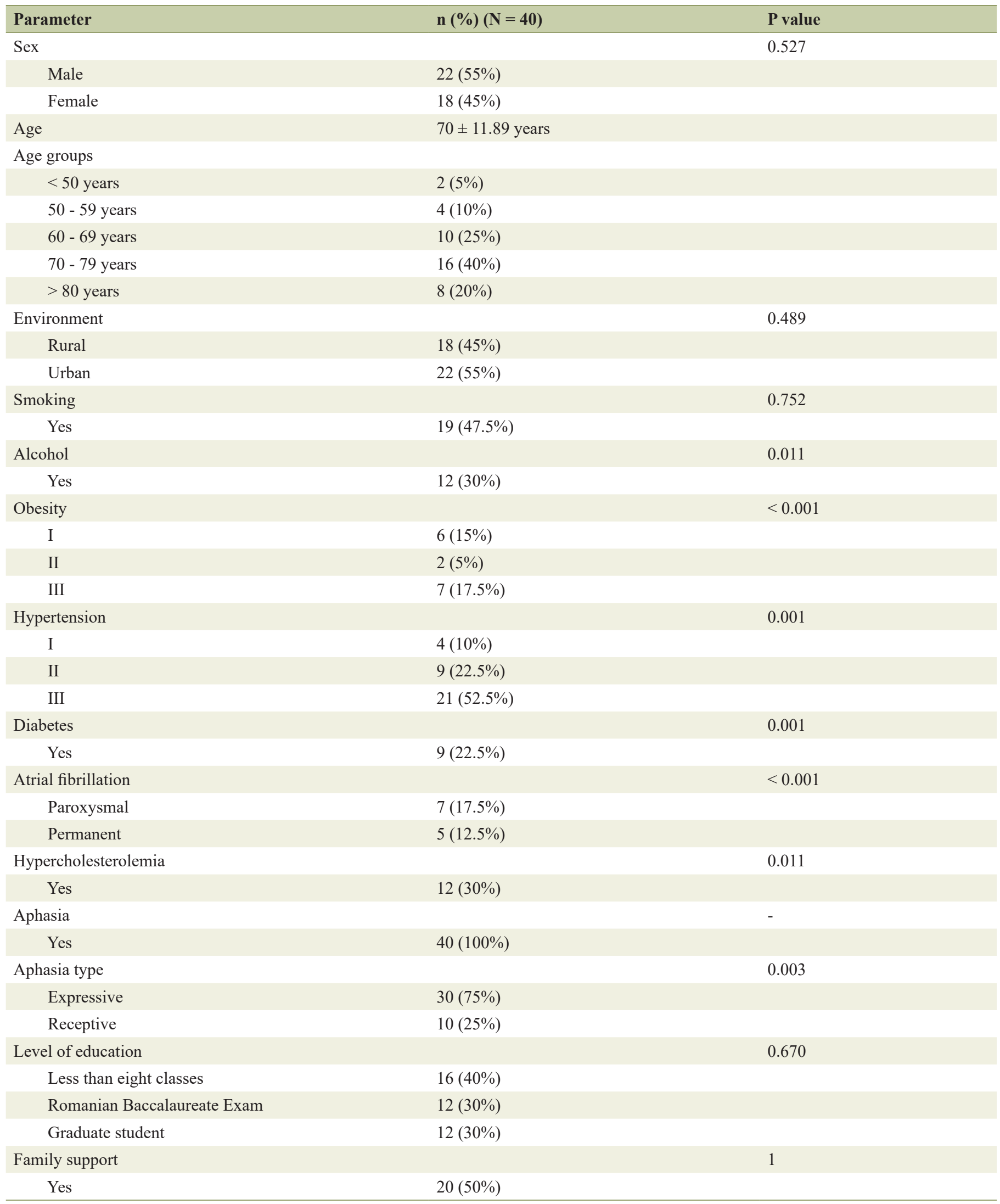


Table 2. Gender Variations of SSQOL Before and After Rehabilitation

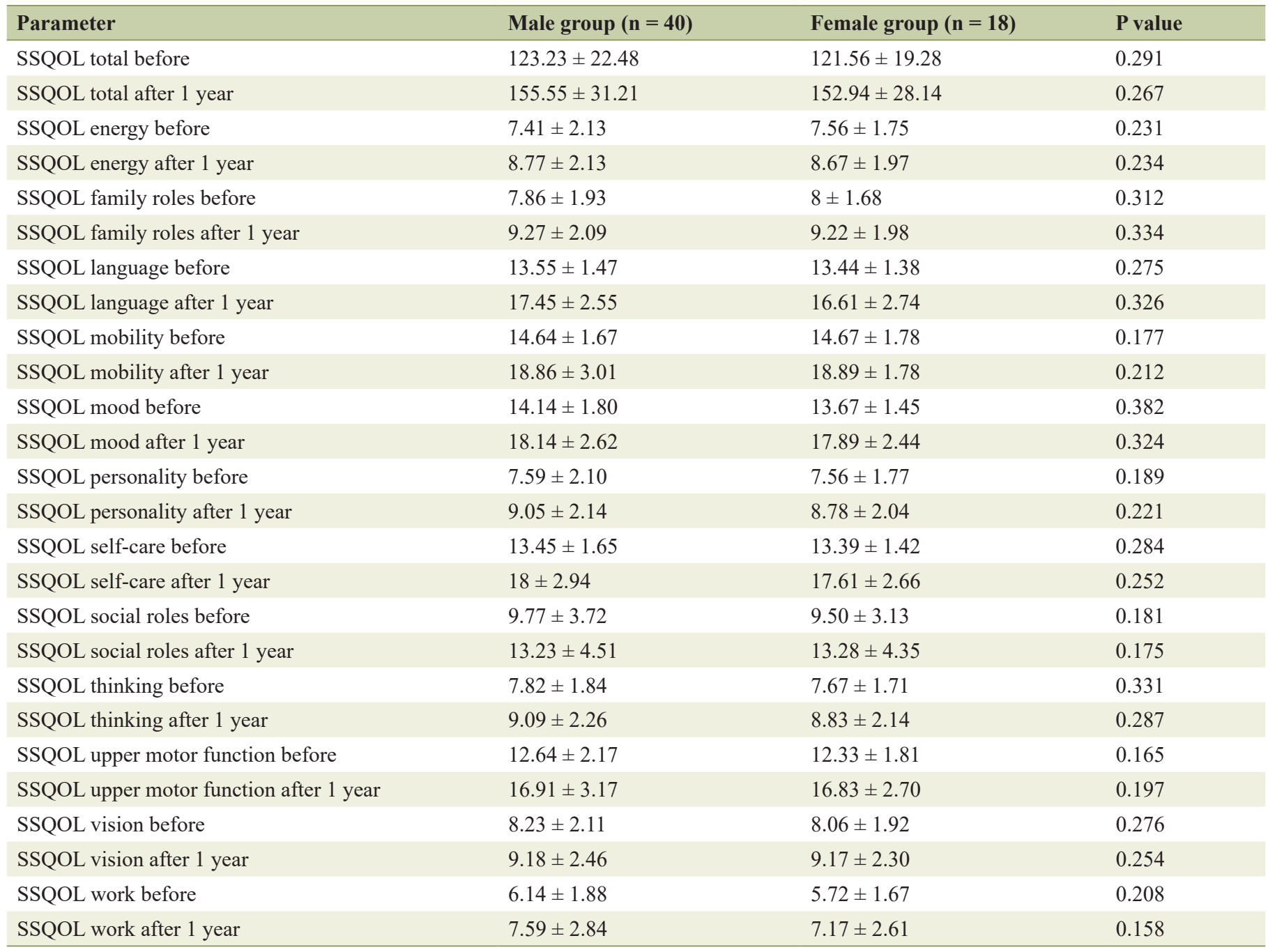

SSQOL: stroke-specific quality of life.

the Declaration of Helsinki.

\section{Results}

The results of the study were divided into two parts: in the first part, a descriptive analysis of the demographic data (gender, age, educational level, living environment and comorbidities) of the group of patients was performed; subsequently, the QOL index was calculated for every member of the group before and after the 1-year period of post-stroke rehabilitation, comparing the results with respect to the individual characteristics mentioned previously.

\section{Individual characteristics}

Regarding the socio-demographic and clinical characteristics of patients, the details are presented in Table 1. More men than women were enrolled in the study group (55\% vs. $45 \%)$. The mean age of these patients was $70 \pm 11.89$ years, corresponding to the decade with an average frequency in the group (parametric demographic with statistically significant value). Most patients enrolled in the present study were from urban areas (55\% of all cases) and were non-smokers and chronically nonconsumers of ethanol. Obesity, high blood pressure, diabetes and atrial fibrillation were statistically significant comorbidities (statistical p 0.001 or $<0.001$ ). All patients included in the study were aphasic, with the predominance of expressive aphasia (statistical $\mathrm{P}=0.003$ ).

\section{SSQOL before and after 1-year rehabilitation program}

Concerning the SSQOL scores, the results were divided according to the total score and the scores of the participants on the subdivisions of the questionnaire as well as according to gender, level of education, living environment and family 
Table 3. Age-Related Progress After Rehabilitation for Patients Below 60 Years

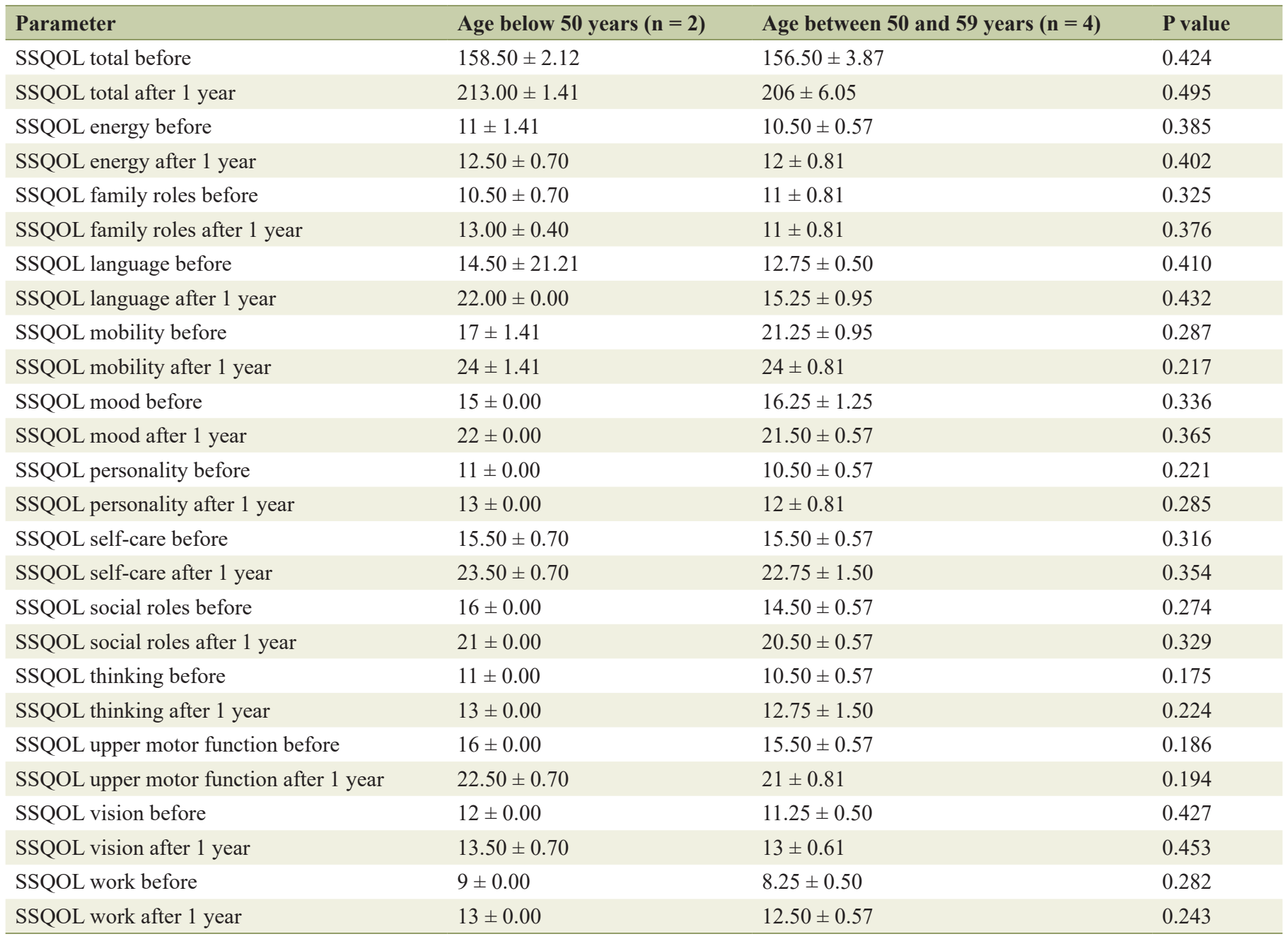

SSQOL: stroke-specific quality of life.

support. No statistically significant differences were observed between SSQOL parameters in female or male patients $(\mathrm{P}=$ 0.267). Both groups registered higher scores after 1 year of rehabilitation, showing a general improvement under therapy: total SSQOL score from $123.23 \pm 22.48$ to $155.55 \pm 31.21$ in men, while in women we assessed a total score improvement from $121.56 \pm 19.28$ to $152.94 \pm 28.14$. Table 2 shows in a more detailed manner the score evolution for all subdomains of the questionnaire.

Regarding the influence of age on rehabilitation process, patients were divided into five subgroups corresponding to decades (Tables 3-5). The statistical analysis registered higher scores in patients under $50(213.00 \pm 1.41)$ and between 50 and $60(206 \pm 6.05)$, compared to older patients (above 60 years), where improvements were lower $(168 \pm 11.87$ for 60 to 70 years old patients, $143.25 \pm 6.38$ for 70 to 80 years old, and only $119.13 \pm 9.92$ in people over 80 .

Younger age has a positive impact on rehabilitation prognosis $(\mathrm{P}=0.005)$, as total score in patients under 60 years $(210$ \pm 8.45 ) was significantly better compared to total score in sub- jects over 60 years $(153.25 \pm 17.38)$ (Table 5). Improvement in language (18.25 \pm 4.95 vs. $17.56 \pm 2.23)$, upper motor function $(21.50 \pm 2.70$ vs. $13.38 \pm 3.25)$ and working ability (12.50 \pm 0.57 vs. $7.14 \pm 1.96$ ) were subdomains where younger had significant higher scores. However, no significant differences were found in values in the age groups under 50 and between 50 and 59 years (total score $\mathrm{P}=0.495$ ) (Table 3 ).

According to our results, the living environment (urban $55 \%$ vs. rural $45 \%$ ) and the educational level (30\% university graduates) also influence stroke rehabilitation. Patients from urban areas scored higher on both the initial assessment $(156.50 \pm 3.87)$ and that after 1 year $(210 \pm 8.45)$ compared to participants from rural areas (121.56 \pm 19.28 before and $158.25 \pm 16.78$ after 1 year of therapy). Moreover, the highest scores were registered in patients with university education $(213.00 \pm 1.41)$ in contrast with patients with eight classes $(119.13 \pm 9.92)$ or Baccalaureate graduation (139.56 \pm 7.23$)$, where no statistical significance was observed $(\mathrm{P}>0.05)$.

The importance of family support in the recovery of these patients was indirectly illustrated by the scores obtained in the 
Table 4. Age-Related Progress After Rehabilitation For Patients Over 60 Years

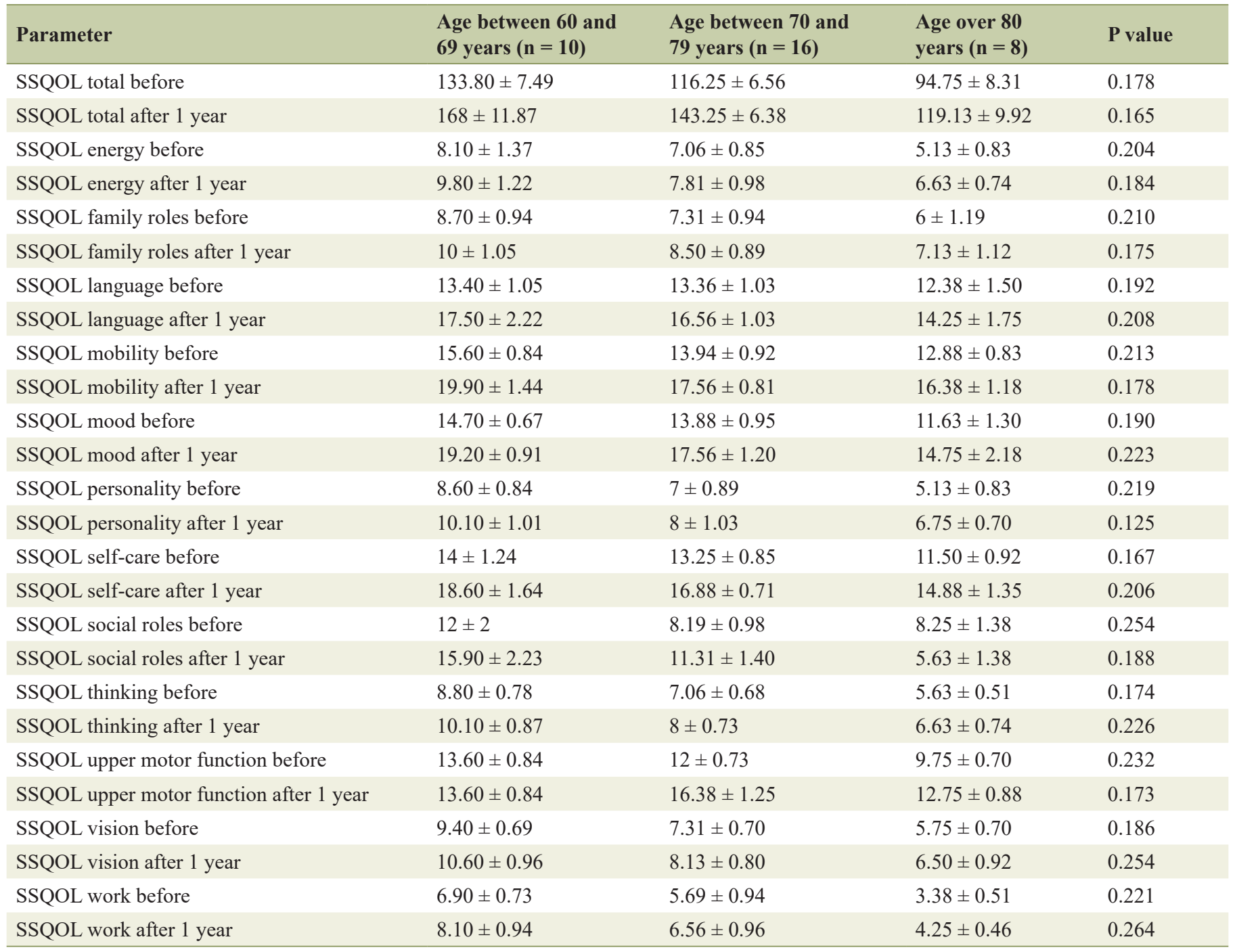

SSQOL: stroke-specific quality of life.

two categories of patients; thus, the first subgroup made up of patients without family support had lower scores both before $(94.75 \pm 7.19$ vs. $110.24 \pm 13.72)$ and after 1 year of rehabilitation $(131.53 \pm 6.79$ vs. $158.62 \pm 10.27)$ with even less progress (36.78 vs. 45.32$)$.

\section{Discussion}

Of all the parameters evaluated after the 12-month rehabilitation treatment, perhaps the most significant aspect for the patient is the improvement of the QOL. An increased index of patient's QOL means better social and work reintegration, a lower requirement for medical care, greater autonomy and lower costs for the insurance system and for the family [30].

According to the present research, an essential factor for predicting QOL after treatment is the patient's age, a result consistent with the literature [31-33]. On the other hand, an- other study demonstrated the variability of the QOL index according to the geographical region [34]. Many studies [34-41] highlight the difference of personal factors correlated to stroke and therapy outcomes for different countries, and although the same rehabilitation treatments were used, it becomes difficult to compare the results of two centers in different countries because of patients' heterogeneity.

Another element that could influence the QOL after treatment is the sex of the patient. We have found several studies in the literature about the influence of gender on QOL after stroke, but no conclusion could be drawn [42-45]. In the current research, we found no correlation between gender and rehabilitation prognosis.

In terms of living environment, however, the results were surprising. According to our data, patients living in urban areas showed a better recovery rate as opposed to those in rural areas. Some explanations in the Romanian context would be as follows: 1) People from rural regions benefit from a low level 
Table 5. Comparison of Extreme Ages Regarding Rehabilitation Progress

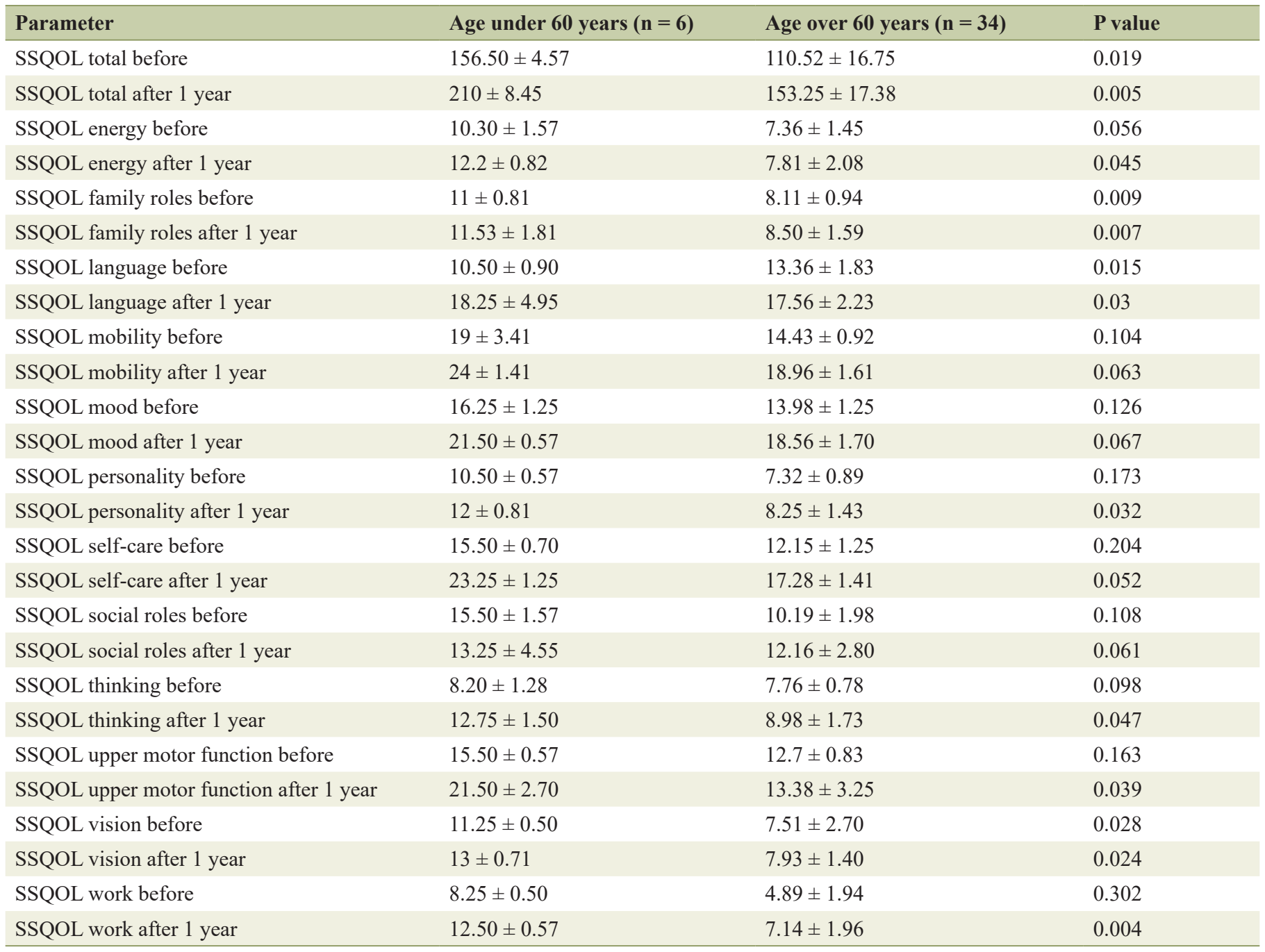

SSQOL: stroke-specific quality of life.

of education, which leads to a greater chance of being nonadherent to the long-term treatment of rehabilitation. 2) There is a significant difference between the revenues allocated to home rehabilitation services in urban and rural areas. 3) In rural regions, there is a lack of medical staff to encourage the active participation of the patient in the therapy.

These explanations are also supported by another correlation that we have determined in the present work: patients with a high level of education (university studies) made the most significant progress in language recovery. Moreover, the fact that most intellectuals were active and wanted a professional reintegration was an additional reason behind the active improvement of their QOL. We did not find studies that directly describe the relationship between the area of living and post-stroke rehabilitation. In studies evaluating the influence of the level of education on rehabilitation [33, 46-49], the direct correlation between a high level of education and a better recovery has been observed; this tendency was also observed in this work.
Comorbidities may influence not only stroke occurrence, but also rehabilitation measures and QOL. In our group, there were numerous patients with associated diseases (obesity, high blood pressure, diabetes and atrial fibrillation) who had altered values of SSQOL index. These data are in line with the literature that shows lower QOL in diabetic patients [50]. Moreover, the combination of more comorbidities can affect both motor function and neuropsychological functions such as memory and cognition [51, 52].

An important dimension that was not explored in this work was the influence of depression installed after stroke on QOL. According to Thompson and Ouden [53], depression is a considerable factor in the acute post-stroke period, affecting $25 \%$ of patients. On the other hand, a study [54] showed that depression is also predominant in the chronic post-stroke period, possibly influencing rehabilitation. The results of other researches showed that QOL was profoundly affected by depression, which also had a negative influence on the function of language [55-58]. 
Finally, family support was found to be an important factor that increases the QOL. All patients living with at least one relative had significantly higher SSQOL indices than those living alone or in nursing homes. Our research data are similar to the results of a study conducted in Portugal and Luxembourg that demonstrated a strong correlation between patient satisfaction and family integration in aphasia rehabilitation therapy [49] as well as other works [59-62].

\section{Limitations and strengths}

This study is a prospective one, and its major strength is the accuracy of data collection, the close follow-up of the patients and the multitude of variables which were studied.

However, this study also has its limitations. Compared to other cohort studies, the dimension of the cohort in this work is small (only 40 patients); this is mostly due to the harsh exclusion criteria which, on the other hand, makes the final result more accurate.

Another limitation of this work would be the absence of the study of depression in the post-stroke context. The correlation between particular damaged areas of the brain after stroke and psychiatric disorders such as depression is a topic of great interest for both neurologists and psychiatrists. However, as the patients from this group are still under monitoring and have the opportunity to re-enter our clinic for continuation of rehabilitation therapy, there is a high possibility to complete this study with references to psychiatric symptoms or other factors thought to influence the rehabilitative process [63-75].

\section{Conclusions}

Stroke is a major health problem in Romania with neurologists focusing more on the subacute and chronic rehabilitation stages.

This work was divided into two parts: first, the socio-demographic and clinical aspects of the group were highlighted, and the second part was dedicated to the study of QOL and its influencing factors. The members of the study group were predominantly men (55\%), with a mean age of $70 \pm 11.89$ years, living in urban areas (55\%), surprisingly non-smokers and chronically non-consumers of ethanol.

Concerning the risk factors, obesity, high blood pressure, diabetes and atrial fibrillation were statistically significant comorbidities (statistical $\mathrm{P} \leq 0.001$ ), which is in line with all studies dedicated to the study of influencing factors for stroke occurrence [34-41, 45, 49-79]. Because stroke occurred in the left middle cerebral artery, all patients included in the study had a low or high degree of aphasia with the predominance of expressive aphasia.

An essential factor for stroke patients is the QOL, which in recent years has been measured using different scales. Although a specific scale (SSQOL) has been developed for patients with stroke, it is subjective and has limitations.

The QOL index depends on many modifiable and unchangeable factors; however, because of the small number of patients in our study, the continuation of research to establish an exact correlation is necessary.

Gender does not influence the outcome of 1-year rehabilitation. Age is a good predictor for rehabilitation as younger patients (under 60 years) improve significantly in their QOL compared to the elderly. Urban domicile and higher educational status (university studies) are positive factors for good rehabilitative probability and a satisfactory outcome. Family support from the very beginning of the rehabilitation therapy benefits the patient.

\section{Acknowledgments}

The author wants to acknowledge Dr. Aurora Constantinescu, the head of the Neurology Department for the scientific support and guidance for this paper at the time of data collection, and speech therapist Mariuta Luminita for the support regarding the information on aphasia. Moreover, special thanks also to Dr. Cristina Adam for the help offered with the statistical analysis.

\section{Financial Disclosure}

All costs regarding study design, research, data collection, analysis and interpretation of data, writing, review and approval of the publication were borne by the author.

\section{Conflict of Interest}

The author states that there was no conflict of interest.

\section{Informed Consent}

Informed consent was taken from all the patients.

\section{Data Availability}

The authors declare that data supporting the findings of this study are available within the article.

\section{References}

1. Carandang R, Seshadri S, Beiser A, Kelly-Hayes M, Kase CS, Kannel WB, Wolf PA. Trends in incidence, lifetime risk, severity, and 30-day mortality of stroke over the past 50 years. JAMA. 2006;296(24):2939-2946.

2. Le Danseur M. Stroke rehabilitation. Crit Care Nurs Clin North Am. 2020;32(1):97-108.

3. Kleim JA, Jones TA. Principles of experience-dependent neural plasticity: implications for rehabilitation after brain damage. J Speech Lang Hear Res. 2008;51(1):S225-239.

4. Lopez AD, Mathers CD, Ezzati M, Jamison DT, Murray 
CJ. Global and regional burden of disease and risk factors, 2001: systematic analysis of population health data. Lancet. 2006;367(9524):1747-1757.

5. Vo TQ, Le PH. Post-stroke rehabilitation cost with traditional therapy: Evidence from a public hospital. J Pak Med Assoc. 2019;69(6 Suppl 2):S87-S95.

6. Di Carlo A, Inzitari D, Galati F, Baldereschi M, Giunta V, Grillo G, Furchi A, et al. A prospective community-based study of stroke in Southern Italy: the Vibo Valentia incidence of stroke study (VISS). Methodology, incidence and case fatality at 28 days, 3 and 12 months. Cerebrovasc Dis. 2003;16(4):410-417.

7. Benjamin EJ, Blaha MJ, Chiuve SE, Cushman M, Das SR, Deo R, de Ferranti SD, et al. Heart disease and stroke statistics-2017 update: a report from the American Heart Association. Circulation. 2017;135(10):e146-e603.

8. Asplund K, Stegmayr B, Peltonen M. From the twentieth to the Twenty-first century: A public health perspective on stroke. In: Ginsberg MD, Bogousslavsky J. (eds.) Cerebrovascular disease: pathophysiology, diagnosis, and management. Blackwell Science, Malden, MA, 1998: 901-918.

9. Rothwell PM, Coull AJ, Silver LE, Fairhead JF, Giles MF, Lovelock CE, Redgrave JN, et al. Population-based study of event-rate, incidence, case fatality, and mortality for all acute vascular events in all arterial territories (Oxford Vascular Study). Lancet. 2005;366(9499):17731783.

10. Ioacara S, Tiu C, Panea C, Nicolae H, Sava E, Martin S, Fica S. Stroke mortality rates and trends in Romania, 19942017. J Stroke Cerebrovasc Dis. 2019;28(12):104431.

11. Chiu D, Peterson L, Elkind MSV, Rosand J, Gerber LM, Silverstein MD, Glycine Antagonist in Neuroprotection Americas Trial Investigators. Comparison of outcomes after intracerebral hemorrhage and ischemic stroke. J Stroke Cerebrovasc Dis. 2010;19(3):225-229.

12. Lo Buono V, Corallo F, Bramanti P, Marino S. Coping strategies and health-related quality of life after stroke. J Health Psychol. 2017;22(1):16-28.

13. Carvalho-Pinto BP, Faria CD. Health, function and disability in stroke patients in the community. Braz J Phys Ther. 2016;20(4):355-366.

14. Leach E, Cornwell P, Fleming J, Haines T. Patient centered goal-setting in a subacute rehabilitation setting. Disabil Rehabil. 2010;32(2):159-172.

15. Pedersen SG, Anke A, Aadal L, Pallesen H, Moe S, Arntzen C. Experiences of quality of life the first year after stroke in Denmark and Norway. A qualitative analysis. Int J Qual Stud Health Well-being. 2019;14(1):1659540.

16. Costanza R, Fisher B, Ali S, Beer C, Bond L, Boumans $\mathrm{R}$, Danigelis NL, et al. An integrative approach to quality of life measurement, research, and policy. S.A.P.I.EN.S. 2008;1(1):11-15.

17. McKevitt C, Redfern J, La-Placa V, Wolfe CD. Defining and using quality of life: a survey of health care professionals. Clin Rehabil. 2003;17(8):865-870.

18. Holroyd S. Urinary incontinence after stroke. Br J Community Nurs. 2019;24(12):590-594.

19. De Wit L, Theuns P, Dejaeger E, Devos S, Gantenbein
AR, Kerckhofs E, Schuback B, et al. Long-term impact of stroke on patients' health-related quality of life. Disabil Rehabil. 2017;39(14):1435-1440.

20. Cappa SF, Benke T, Clarke S, Rossi B, Stemmer B, van Heugten CM, Task Force on Cognitive R, et al. EFNS guidelines on cognitive rehabilitation: report of an EFNS task force. Eur J Neurol. 2005;12(9):665-680.

21. Cicerone KD, Dahlberg C, Malec JF, Langenbahn DM, Felicetti T, Kneipp S, Ellmo W, et al. Evidence-based cognitive rehabilitation: updated review of the literature from 1998 through 2002. Arch Phys Med Rehabil. 2005;86(8):1681-1692.

22. Seidel G, Rottinger A, Lorenzen J, Kucken D, Majewski A, Klose K, Terborg C, et al. [Quality of life and disability after severe stroke and early neurological rehabilitation]. Nervenarzt. 2019;90(10):1031-1036.

23. Skoglund E, Westerlind E, Persson HC, Sunnerhagen KS. Self-perceived impact of stroke: A longitudinal comparison between one and five years post-stroke. J Rehabil Med. 2019;51(9):660-664.

24. Hilari K, Owen S, Farrelly SJ. Proxy and self-report agreement on the Stroke and Aphasia Quality of Life Scale-39. J Neurol Neurosurg Psychiatry. 2007;78(10):1072-1075.

25. Silva SM, Correa FI, Faria CD, Correa JC. Psychometric properties of the stroke specific quality of life scale for the assessment of participation in stroke survivors using the rasch model: a preliminary study. J Phys Ther Sci. 2015;27(2):389-392.

26. Lima RCM, Teixeira-Salmela LF, Magalhaes LC, GomesNeto M. Propriedades psicometricas da versao brasileira da escala de qualidade de vida especifica para acidente vascular encefalico: aplicacao do modelo Rasch. Rev Bras fisioter. 2008;12:149-156.

27. Hsueh IP, Jeng JS, Lee Y, Sheu CF, Hsieh CL. Construct validity of the stroke-specific quality of life questionnaire in ischemic stroke patients. Arch Phys Med Rehabil. 2011;92(7):1113-1118.

28. Legris N, Devilliers H, Daumas A, Carnet D, Charpy JP, Bastable P, Giroud M, et al. French validation of the Stroke Specific Quality of Life Scale (SS-QoL). NeuroRehabilitation. 2018;42(1):17-27.

29. Hakverdioglu Yont G, Khorshid L. Turkish version of the Stroke-Specific Quality of Life Scale. Int Nurs Rev. 2012;59(2):274-280.

30. Bindawas SM, Vennu V, Mawajdeh $\mathrm{H}$, Alhaidary $\mathrm{H}$. Functional outcomes by age after inpatient stroke rehabilitation in Saudi Arabia. Clin Interv Aging. 2017;12:17911797.

31. Meiner Z, Feintuch U, Sajin A, Yovchev I, Gartsman I, Moreh E, Tsenter J, et al. Rehabilitation outcomes of patients with stroke: effect of age on functional outcome and discharge destination. Topics in Geriatric Rehabilitation. 2015;31(2):138-144.

32. Katona M, Schmidt R, Schupp W, Graessel E. Predictors of health-related quality of life in stroke patients after neurological inpatient rehabilitation: a prospective study. Health Qual Life Outcomes. 2015;13:58.

33. Haley WE, Roth DL, Kissela B, Perkins M, Howard G. Quality of life after stroke: a prospective longitudinal 
study. Qual Life Res. 2011;20(6):799-806.

34. Sprigg N, Gray LJ, Bath PM, Christensen H, De Deyn PP, Leys D, O'Neill D, et al. Quality of life after ischemic stroke varies in western countries: data from the tinzaparin in Acute Ischaemic Stroke Trial (TAIST). J Stroke Cerebrovasc Dis. 2012;21(7):587-593.

35. Khoshbakht Pishkhani M, Dalvandi A, Ebadi A, Hosseini M. Factors affecting adherence to rehabilitation in Iranian stroke patients: A qualitative study. J Vasc Nurs. 2019;37(4):264-271.

36. Ezeugwu VE, Manns PJ. Sleep Duration, Sedentary Behavior, Physical Activity, and Quality of Life after Inpatient Stroke Rehabilitation. J Stroke Cerebrovasc Dis. 2017;26(9):2004-2012.

37. Schinwelski MJ, Sitek EJ, Waz P, Slawek JW. Prevalence and predictors of post-stroke spasticity and its impact on daily living and quality of life. Neurol Neurochir Pol. 2019;53(6):449-457.

38. Mahesh PKB, Gunathunga MW, Jayasinghe S, Arnold SM, Liyanage SN. Factors influencing pre-stroke and post-stroke quality of life among stroke survivors in a lower middle-income country. Neurol Sci. 2018;39(2):287295.

39. Khalid W, Rozi S, Ali TS, Azam I, Mullen MT, Illyas S, Un-Nisa Q, et al. Quality of life after stroke in Pakistan. BMC Neurol. 2016;16(1):250.

40. Wang R, Langhammer B. Predictors of quality of life for chronic stroke survivors in relation to cultural differences: a literature review. Scand J Caring Sci. 2018;32(2):502514.

41. Heikinheimo T, Chimbayo D. Quality of life after firstever stroke: An interview-based study from Blantyre, Malawi. Malawi Med J. 2015;27(2):50-54.

42. Zalihic A, Markotic V, Zalihic D, Mabic M. Gender and quality of life after cerebral stroke. Bosn J Basic Med Sci. 2010;10(2):94-99.

43. Franzen-Dahlin A, Laska AC. Gender differences in quality of life after stroke and TIA: a cross-sectional survey of out-patients. J Clin Nurs. 2012;21(15-16):2386-2391.

44. Buijck BI, Zuidema SU, Spruit-van Eijk M, Bor H, Gerritsen DL, Koopmans RT. Determinants of geriatric patients' quality of life after stroke rehabilitation. Aging Ment Health. 2014;18(8):980-985.

45. Hou WH, Ni CH, Li CY, Tsai PS, Lin LF, Shen HN. Stroke rehabilitation and risk of mortality: a populationbased cohort study stratified by age and gender. J Stroke Cerebrovasc Dis. 2015;24(6):1414-1422.

46. Fernandes TG, Goulart AC, Santos-Junior WR, Alencar AP, Bensenor IM, Lotufo PA. Educational levels and the functional dependence of ischemic stroke survivors. Cad Saude Publica. 2012;28(8):1581-1590.

47. Lopez-Espuela F, Zamorano JD, Ramirez-Moreno JM, Jimenez-Caballero PE, Portilla-Cuenca JC, LavadoGarcia JM, Casado-Naranjo I. Determinants of quality of life in stroke survivors after 6 months, from a comprehensive stroke unit: a longitudinal study. Biol Res Nurs. 2015;17(5):461-468.

48. Chen CM, Tsai CC, Chung CY, Chen CL, Wu KP, Chen HC. Potential predictors for health-related quality of life in stroke patients undergoing inpatient rehabilitation. Health Qual Life Outcomes. 2015;13:118.

49. Baumann M, Lurbe K, Leandro ME, Chau N. Life satisfaction of two-year post-stroke survivors: effects of socio-economic factors, motor impairment, Newcastle stroke-specific quality of life measure and World Health Organization quality of life: bref of informal caregivers in Luxembourg and a rural area in Portugal. Cerebrovase Dis. 2012;33(3):219-230.

50. Nichols-Larsen DS, Clark PC, Zeringue A, Greenspan A, Blanton S. Factors influencing stroke survivors' quality of life during subacute recovery. Stroke. 2005;36(7):14801484.

51. Thilarajah S, Mentiplay BF, Bower KJ, Tan D, Pua YH, Williams G, Koh G, et al. Factors associated with poststroke physical activity: a systematic review and metaanalysis. Arch Phys Med Rehabil. 2018;99(9):1876-1889.

52. Munce SEP, Perrier L, Shin S, Adhihetty C, Pitzul K, Nelson MLA, Bayley MT. Strategies to improve the quality of life of persons post-stroke: protocol of a systematic review. Syst Rev. 2017;6(1):184.

53. Thompson CK, den Ouden DB. Neuroimaging and recovery of language in aphasia. Curr Neurol Neurosci Rep. 2008;8(6):475-483.

54. Marcotte K, Ansaldo AI. The neural correlates of semantic feature analysis in chronic aphasia: discordant patterns according to the etiology. Semin Speech Lang. 2010;31(1):52-63.

55. Marima P, Gunduza R, Machando D, Dambi JM. Correlates of social support on report of probable common mental disorders in Zimbabwean informal caregivers of patients with stroke: a cross-sectional survey. BMC Res Notes. 2019;12(1):514.

56. Bullier B, Cassoudesalle H, Villain M, Cogne M, Mollo C, De Gabory I, Dehail P, et al. New factors that affect quality of life in patients with aphasia. Ann Phys Rehabil Med. 2020;63(1):33-37.

57. Chiba R, Tominaga S, Mikami K, Kitajima M, Urushizaka M, Tomisawa T, Chiba J, et al. Factors influencing quality of life in stroke patients: focus on eating habits. J Stroke Cerebrovasc Dis. 2019;28(6):1623-1628.

58. van Mierlo ML, van Heugten CM, Post MW, Hajos TR, Kappelle LJ, Visser-Meily JM. Quality of life during the first two years post stroke: the restore4stroke cohort study. Cerebrovasc Dis. 2016;41(1-2):19-26.

59. Brown K, Worrall L, Davidson B, Howe T. Living successfully with aphasia: family members share their views. Top Stroke Rehabil. 2011;18(5):536-548.

60. Lehnerer S, Hotter B, Padberg I, Knispel P, Remstedt D, Liebenau A, Grittner U, et al. Social work support and unmet social needs in life after stroke: a cross-sectional exploratory study. BMC Neurol. 2019;19(1):220.

61. Broussy S, Saillour-Glenisson F, Garcia-Lorenzo B, Rouanet F, Lesaine E, Maugeais M, Aly F, et al. Sequelae and quality of life in patients living at home 1 year after a stroke managed in stroke units. Front Neurol. 2019;10:907.

62. Lam KH, Blom E, Kwa VIH. Predictors of quality of life 1 year after minor stroke or TIA: a prospective single- 
centre cohort study. BMJ Open. 2019;9(11):e029697.

63. Robinson RG. Poststroke depression: prevalence, diagnosis, treatment, and disease progression. Biol Psychiatry. 2003;54(3):376-387.

64. Sivolap YP, Damulin IV. [Stroke and depression]. Zh Nevrol Psikhiatr Im S S Korsakova. 2019;119(9):143147.

65. Denissen S, Staring W, Kunkel D, Pickering RM, Lennon S, Geurts $\mathrm{ACH}$, Weerdesteyn $\mathrm{V}$, et al. Interventions for preventing falls in people after stroke. Stroke. 2020;51(3):e47-e48.

66. Kim WH, Yoo YH, Lim JY, Kang SG, Jung HY, Bae JN, Joa KL. Objective and subjective sleep problems and quality of life of rehabilitation in patients with mild to moderate stroke. Top Stroke Rehabil. 2020;27(3):199207.

67. Maier M, Ballester BR, Verschure P. Principles of neurorehabilitation after stroke based on motor learning and brain plasticity mechanisms. Front Syst Neurosci. 2019;13:74.

68. Yeoh YS, Koh GC, Tan CS, Tu TM, Singh R, Chang HM, De Silva DA, et al. Health-related quality of life loss associated with first-time stroke. PLoS One. 2019;14(1):e0211493.

69. Opara JA, Jaracz K. Quality of life of post-stroke patients and their caregivers. J Med Life. 2010;3(3):216-220.

70. Cerniauskaite M, Quintas R, Koutsogeorgou E, Meucci P, Sattin D, Leonardi M, Raggi A. Quality-of-life and disability in patients with stroke. Am J Phys Med Rehabil. 2012;91(13 Suppl 1):S39-47.

71. Ranford J, Asiello J, Cloutier A, Cortina K, Thorne H, Erler KS, Frazier N, et al. Interdisciplinary stroke recov- ery research: the perspective of occupational therapists in acute care. Front Neurol. 2019;10:1327.

72. Loetscher T, Potter KJ, Wong D, das Nair R. Cognitive rehabilitation for attention deficits following stroke. Cochrane Database Syst Rev. 2019;2019(11).

73. Egan MY, Kessler D, Ceci C, Laliberte-Rudman D, McGrath C, Sikora L, Gardner P. Problematising risk in stroke rehabilitation. Disabil Rehabil. 2016;38(23):23342344.

74. Lee H, Lee Y, Choi H, Pyun SB. Community integration and quality of life in aphasia after stroke. Yonsei Med J. 2015;56(6):1694-1702.

75. Singhpoo K, Charerntanyarak L, Ngamroop R, Hadee N, Chantachume W, Lekbunyasin O, Sawanyawisuth K, et al. Factors related to quality of life of stroke survivors. J Stroke Cerebrovasc Dis. 2012;21(8):776-781.

76. Rohling ML, Faust ME, Beverly B, Demakis G. Effectiveness of cognitive rehabilitation following acquired brain injury: a meta-analytic re-examination of Cicerone et al.'s $(2000,2005)$ systematic reviews. Neuropsychology. 2009;23(1):20-39.

77. Vluggen T, van Haastregt JCM, Tan FES, Kempen G, Schols J, Verbunt JA. Factors associated with successful home discharge after inpatient rehabilitation in frail older stroke patients. BMC Geriatr. 2020;20(1):25.

78. Koleck M, Gana K, Lucot C, Darrigrand B, Mazaux JM, Glize B. Quality of life in aphasic patients 1 year after a first stroke. Qual Life Res. 2017;26(1):45-54.

79. Hou L, Du X, Chen L, Li J, Yan P, Zhou M, Zhu C. Exercise and quality of life after first-ever ischaemic stroke: a twoyear follow-up study. Int J Neurosci. 2018;128(6):540548. 